\title{
Study on Strength and Microstructure of Cement-Based Materials Containing Combination Mineral Admixtures
}

\author{
Meijuan Rao, ${ }^{1,2}$ Jianpeng Wei, ${ }^{3}$ Zhiyang Gao, $^{2}$ Wei Zhou, ${ }^{3}$ Qiaoling Li, ${ }^{3}$ and Shuhua Liu ${ }^{3}$ \\ ${ }^{1}$ State Key Laboratory of Silicate Materials for Architectures, Wuhan University of Technology, \\ Wuhan 430070, China \\ ${ }^{2}$ Changjiang River Scientific Research Institute, Wuhan 430010, China \\ ${ }^{3}$ State Key Laboratory of Water Resources and Hydropower Engineering Science, Wuhan University, \\ Wuhan 430072, China \\ Correspondence should be addressed to Shuhua Liu; shliu@whu.edu.cn
}

Received 17 March 2016; Accepted 26 June 2016

Academic Editor: Osman Gencel

Copyright (C) 2016 Meijuan Rao et al. This is an open access article distributed under the Creative Commons Attribution License, which permits unrestricted use, distribution, and reproduction in any medium, provided the original work is properly cited.

\begin{abstract}
The compressive strength of complex binders containing two or three blended mineral admixtures in terms of glass powder (GP), limestone powder (LP), and steel slag powder (SP) was determined by a battery solution type compressive testing machine. The morphology and microstructure characteristics of complex binder hydration products were also studied by microscopic analysis methods, such as XRD, TG-DTA, and SEM. The mechanical properties of the cement-based materials were analyzed to reveal the most appropriate mineral admixture type and content. The early sample strength development with GP was very slow, but it rapidly grew at later stages. The micro aggregate effect and pozzolanic reaction mutually occurred in the mineral admixture. In the early stage, the micro aggregate effect reduced paste porosity and the small particles connected with the cement hydration products to enhance its strength. In the later stage, the pozzolanic reaction of some components in the complex powder occurred and consumed part of the calcium hydroxide to form C-S-H gel, thus improving the hydration environment. Also, the produced C-S-H gel made the structure more compact, which improved the structure's strength.
\end{abstract}

\section{Introduction}

Cement in modern civil engineering is the most versatile and commonly used construction material [1-3]; unfortunately, cement production is energy-consuming and results in large quantities of $\mathrm{CO}_{2}$ emissions [4]. In China, industrial production and everyday life produce large amounts of solid waste, such as steel slag generated by steel production, limestone chips, and powder derived from stone processing, mining, and waste glass produced from human's urban construction [3-6]. These materials occupy numerous valuable land resources and pollute the environment. Therefore, incorporating these three admixtures into cement or concrete could reduce waste products and save expenses related to cement production [7-9].

National and international studies have shown that adding finely ground glass powder (GP), limestone powder (LP), and steel slag powder (SP) to concrete will improve the concrete's mechanical properties, performance, and durability in varying degrees by improving the hydration environment, the micro aggregate effect, and the pozzolanic effect $[6,10-12]$. As we know from previous studies, glass powder, because of its high $\left(\mathrm{SiO}_{2}+\mathrm{Al}_{2} \mathrm{O}_{3}\right) / \mathrm{CaO}$ ratio rate, promotes pozzolanic activity at late stage [13-17]. On the contrary, limestone powder is an inert material; its main component, $\mathrm{CaCO}_{3}$, manifests itself by improving early compressive strength by filling pores and by accelerating the hydration process of the complex binder in the early curing ages. Steel slag powder, composed mainly of $\mathrm{C}_{2} \mathrm{~A}$ and $\mathrm{C}_{3} \mathrm{~A}$, is similar to clinkers; it has potential hydraulic properties and reaction activity that is significantly lower than that of clinkers [18-21].

As civil engineering materials science research has progressed, scholars have found that concrete and cement with combined admixtures could achieve even more favorable performance compared with single-admixture concrete $[22,23]$. However, no literature has systematically studied composite 
TABLE 1: Physical properties of cement (wt.\%).

\begin{tabular}{ccccccc}
\hline Materials & Density $\left(\mathrm{g} / \mathrm{cm}^{3}\right)$ & $\begin{array}{c}\text { Standard water } \\
\text { consumption } \\
(\%)\end{array}$ & $\begin{array}{c}80 \mu \mathrm{m} \text { sieving } \\
\text { residue }(\%)\end{array}$ & $\begin{array}{c}\text { Specific surface } \\
\left(\mathrm{m}^{2} / \mathrm{kg}\right)\end{array}$ & $\begin{array}{c}\text { Stability } \\
\text { Primary setting }\end{array}$ & Final setting \\
\hline Cement & 3.1 & 25.6 & 1.4 & 437 & Qualified & $3: 25$ \\
\hline
\end{tabular}

TABLE 2: Physical properties of limestone powder.

\begin{tabular}{lcccc}
\hline $45 \mu \mathrm{m}$ sieving residue (\%) & Specific surface $\left(\mathrm{m}^{2} / \mathrm{kg}\right)$ & Water demand ratio (\%) & Density $\left(\mathrm{g} / \mathrm{cm}^{3}\right)$ & $\begin{array}{r}\text { Activity index } \\
7 \mathrm{~d}\end{array}$ \\
\hline 16.0 & 457.9 & 98 & 2.69 & 64.1 \\
\hline
\end{tabular}

TABLE 3: Physical properties of glass powder and steel powder.

\begin{tabular}{lccc}
\hline Materials & Density $\left(\mathrm{g} / \mathrm{cm}^{3}\right)$ & Fineness & Specific surface $\left(\mathrm{m}^{2} / \mathrm{kg}\right)$ \\
\hline Glass powder & 2.35 & $80 \mu \mathrm{m}$ sieving residue $(\%)$ & 230 \\
Steel powder & 3.29 & 95 & 265 \\
\hline
\end{tabular}

cementitious materials with the combined admixtures of GP, LP, and SP.

Therefore, to improve the utilization of concrete with the above admixtures, this paper studies the influence of complex mineral admixtures on the macro and micro performances of complex binders, as well as the mineral activity index material evaluation method to characterize the contribution of the hydration activity of mineral admixture to paste strength.

\section{Experimental Materials and Methods}

2.1. Materials. Ordinary Portland Cement (NPC) P.O 42.5 from Huaxin Cement Co. Ltd. (Hubei Province, China) was used. The physical properties of cement and admixtures are shown in Tables 1, 2, and 3. And the chemical compositions of cement and admixtures are shown in Table 4.

2.2. Testing Methods. Group GL, Group GS, Group LS, and Group GLS with the same cement replacement ratios $(15,30$, and $45 \%$ ) were established to analyze the influence of the composite mineral admixtures on the mechanical and hydration characteristics of cement-based materials compared with a pure cement control sample. Table 5 lists the paste mix proportions.

Paste specimens with $40 \mathrm{~mm} \times 40 \mathrm{~mm} \times 40 \mathrm{~mm}$ dimensions and a 0.4 water-to-solid ratio $(\mathrm{W} / \mathrm{C})$ were molded and cured with higher than $90 \%$ relative humidity and $20 \pm 2^{\circ} \mathrm{C}$ temperature until the stipulated age of 7, 28, and 90 days. Determining the compressive strength of paste specimens of different ages was conducted by WAY-2000 (i.e., a battery solution type compressive testing machine). Clean, bean-size samples were taken from the center of the broken specimens and packed into ampere bottles filled up with absolute ethanol to terminate the hydration process before the XRD, TG-DTA, and SEM microcosmic analysis. Sample pieces were held in a dry environment at $60^{\circ} \mathrm{C}$ for 2 or 3 hours before SEM tests. The other samples were ground in an agate mortar and dried at $60^{\circ} \mathrm{C}$ for 2 hours to reduce carbonation before the XRD test and then dried in vacuum condition before the TG-DTA test.

The XRD analysis was made by X-ray diffraction using a copper target and a continuous scan machine produced by RIGAKU, a Japanese company. The TG-DTA in $\mathrm{N}_{2}$ atmosphere up to a temperature of $1200^{\circ} \mathrm{C}$ adopted the diamond TG/DTA analysis produced by Perkin Elmer Instruments Plant, and the morphology of the products was investigated using scanning electron microscopy (JSM-5610LV, Japan).

\section{Results and Discussion}

3.1. Paste Strength. In Figure 1(a), the influence of combined admixture of GP and LP on the compressive strength of cement-based materials involved the characteristics of both GP and LP. When the content of GP and LP reached $15 \%$, the incorporation of GP and LP compensated for the shortcomings of each other because GP has high pozzolanic activity, which causes high latter compressive strength but low strength at the early stage because of its deficient hydralization. The effect of LP on complex binder compressive strength shows just the opposite. For Groups GL2 and GL1, compressive strength was higher at $90 \mathrm{~d}$ than at $28 \mathrm{~d}$. The reason is that, in a certain range, LP incorporation promoted early hydration in the cement, which increased paste strength. When the content reached $45 \%$, the paste's compressive strength rapidly reduced due to the relative amount of decreased cement, which weakened the hydration products. As a result, the paste's compressive strength was not improved.

From Figure 1(b), the compressive strength of samples GP and SP decrease with the increasing of GP and SP content. When the content is $15 \%$, the compressive strength of $7 \mathrm{~d}$ and $90 \mathrm{~d}$ is close to that of the NPC group. The reason may be that, at the early stage, the ground steel slag powder can fill the pore system and integrate with the product so the system becomes dense and the strength 


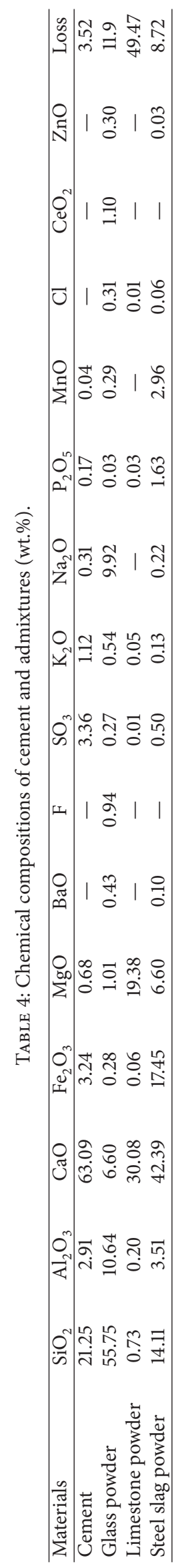


TABLE 5: Mix proportion of pastes and compressive strength of paste/MPa.

\begin{tabular}{|c|c|c|c|c|c|c|c|c|}
\hline \multirow{2}{*}{ Samples } & \multirow{2}{*}{$\begin{array}{l}\text { Mineral admixture } \\
\text { content }(\%)\end{array}$} & \multirow{2}{*}{ Cement (g) } & \multirow{2}{*}{$\begin{array}{l}\text { Glass powder } \\
(\mathrm{g})\end{array}$} & \multirow{2}{*}{$\begin{array}{l}\text { Limestone } \\
\text { powder }(\mathrm{g})\end{array}$} & \multirow{2}{*}{$\begin{array}{l}\text { Steel slag } \\
\text { powder (g) }\end{array}$} & \multicolumn{3}{|c|}{ Compressive strength (MPa) } \\
\hline & & & & & & $7 \mathrm{~d}$ & $28 \mathrm{~d}$ & $90 \mathrm{~d}$ \\
\hline NPC & 0 & 1.00 & - & - & - & 31.5 & 55.3 & 58.0 \\
\hline GL1 & 15 & 0.85 & 0.075 & 0.075 & - & 23.5 & 40.6 & 50.6 \\
\hline GL2 & 30 & 0.7 & 0.15 & 0.15 & - & 18.8 & 28.8 & 41.9 \\
\hline GL3 & 45 & 0.55 & 0.225 & 0.225 & - & 12.4 & 26.2 & 38.2 \\
\hline GS1 & 15 & 0.85 & 0.075 & - & 0.075 & 29.1 & 44.4 & $\overline{52.2}$ \\
\hline GS2 & 30 & 0.7 & 0.15 & - & 0.15 & 19.5 & 32.7 & 41.7 \\
\hline GS3 & 45 & 0.55 & 0.225 & - & 0.225 & 13.9 & 27.0 & 33.9 \\
\hline LS1 & 15 & 0.85 & - & 0.075 & 0.075 & 32.2 & 48.4 & 58.9 \\
\hline LS2 & 30 & 0.7 & - & 0.15 & 0.15 & 31.8 & 39.0 & 49.6 \\
\hline LS3 & 45 & 0.55 & - & 0.225 & 0.225 & 19.8 & 29.3 & 36.1 \\
\hline GLS1 & 15 & 0.85 & 0.05 & 0.05 & 0.05 & 32.6 & 50.2 & 56.6 \\
\hline GLS2 & 30 & 0.7 & 0.1 & 0.1 & 0.1 & 23.2 & 40.9 & 44.7 \\
\hline GLS3 & 45 & 0.55 & 0.15 & 0.15 & 0.15 & 17.2 & 28.9 & 32.0 \\
\hline
\end{tabular}

Notes. G: glass; L: limestone; S: steel slag.

improves eventually. However, the late hydration of the steel slag powder will produce calcium hydroxide and release it into the pore solution to increase the alkalinity. The volcanic ash reaction of the glass powder needs some basic excitation and the hydration process consumes a portion of calcium hydroxide which will promote the hydrate of steel slag. Again, when the content is $30 \%$ or above, the cement content is relatively smaller and the hydration products are insufficient. As a result, there is no promotion in the hydration of the GP and SP at the later stage. The compressive strength of Group GS at each age is significantly lower than that of NPC group and, thus, there is no improvement of the early and late strength.

From Figure 1(c), the compressive strength of each specimen containing LP and SP increased over time. The compressive strength at 7 days changed based on content; it increased initially and then decreased. Furthermore, at 30\%, the intensity reached its maximum and it showed high strength in the early stages. The strength increased with age; however, the compressive strength of the paste at 90 days was similar to that at 7 days, which increased initially and then decreased. The compressive strength at 28 days gradually decreased with the increase of content. The reason is that the finely ground SP and LP at the early stage promoted cement and micro material hydration, which enhanced paste strength. Moreover, the slow hydration of the steel slag powder was favorable for enhancing strength at the latter stage.

From Figure 1(d), the strength increased with age. For the trimix with GP, LP, and SP, $15 \%$ of the content of the specimens in the early and late stages showed good strength performance, and the strength was greater than that of the NPC at 7 days. Due to the slower hydration of glass powder and steel powder, the compressive strength at 28 days is lower than that with NPC. Moreover, the strength at 90 days was basically the same as the NPC. The reason is that the quaternary system of NPC, GP, LP, and SP becomes perfect. Thus, the micro aggregate effect of the micro powder was fully exerted, so the hardened paste porosity was reduced. The volcanic ash interaction effect promoted further cement hydration, causing the system to become more compact.

3.2. Contribution Rates of the Hydration Activity Effect. Figure 1 shows the compressive strength of cement pastes with bi- or trimixed admixtures at different ages.

An evaluation methodology of the activity index of the mineral materials is adopted to evaluate the activity of the glass powder. The calculation steps of this methodology are as follows. The contribution of unit cement consumption (meaning 1\% cement consumption) to concrete strength is called concrete-cement consumption ratio strength or concrete ratio strength for short [18-20]. Hence,

$$
R_{s a}=\frac{R_{a}}{q_{0}} .
$$

$R_{a}$ is the absolute value of concrete strength mixed with auxiliary gel materials. $q_{0}$ is the mass fraction of cement in a system mixed with auxiliary gel materials.

In contrast, the benchmark concrete has a mass fraction of cement $q_{0}$ of $100 \%$. The ratio strength is calculated via

$$
R_{s c}=\frac{R_{c}}{100}
$$

where $R_{c}$ is the absolute value of benchmark concrete.

Although the cement consumption of concrete mixed with auxiliary gel materials decreases, the potentiation effect due to hydration activity effect often makes $R_{a}$ greater than $R_{c}$ and also $R_{s a}$ greater than $R_{s c}[21,22]$. The difference between $R_{s a}$ and $R_{s c}$ is called the hydration activity effect ratio strength and the formula is expressed as follows:

$$
R_{s p}=R_{s a}-R_{s c}
$$




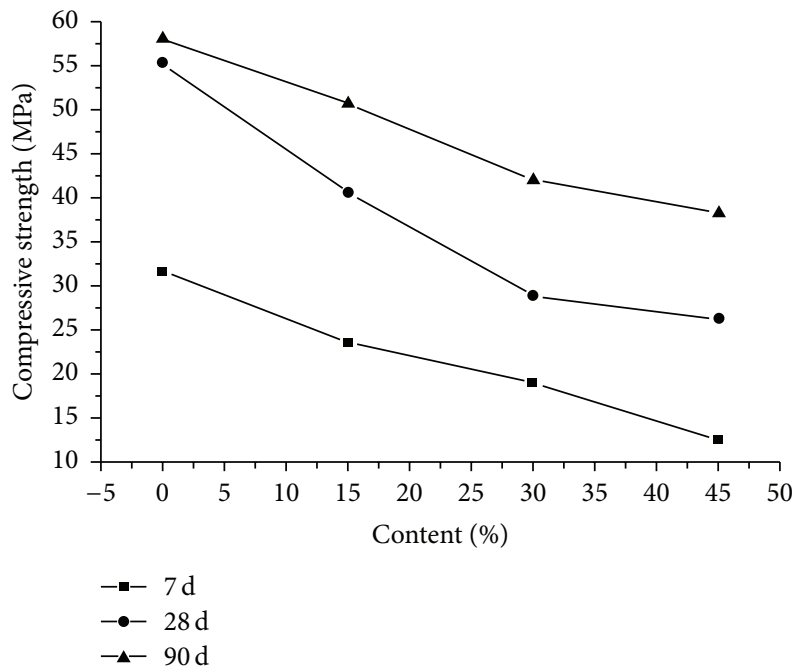

(a) Compressive strength of Group GL

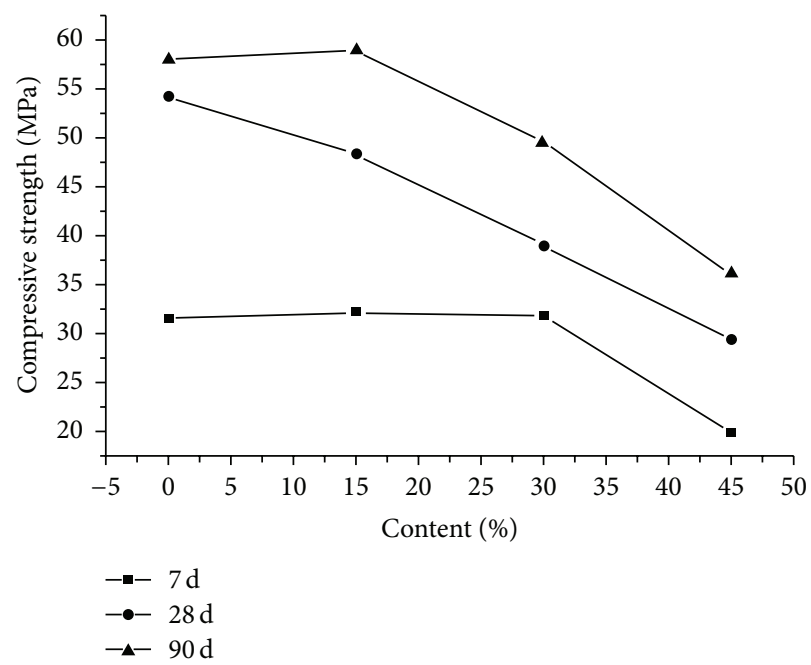

(c) Compressive strength of Group LS

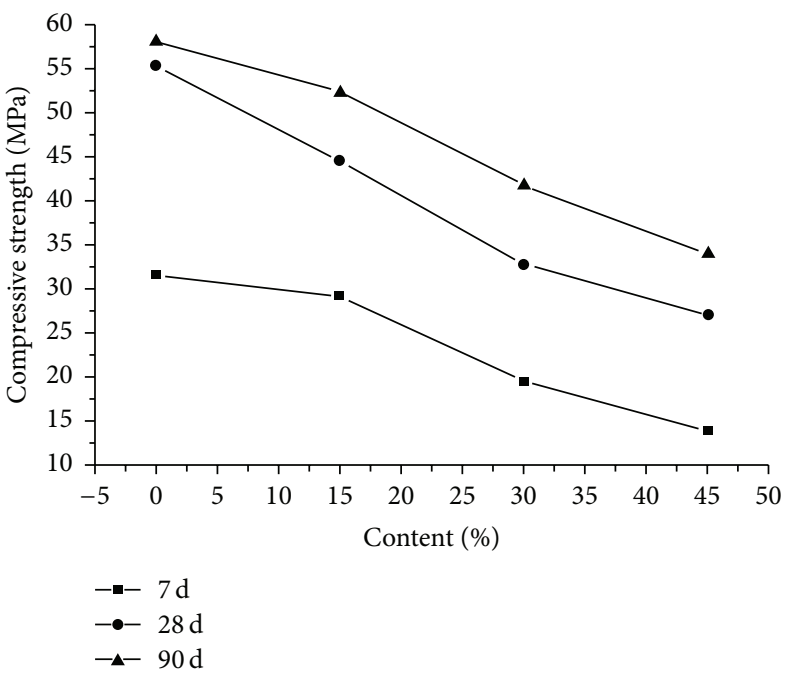

(b) Compressive strength of Group GS

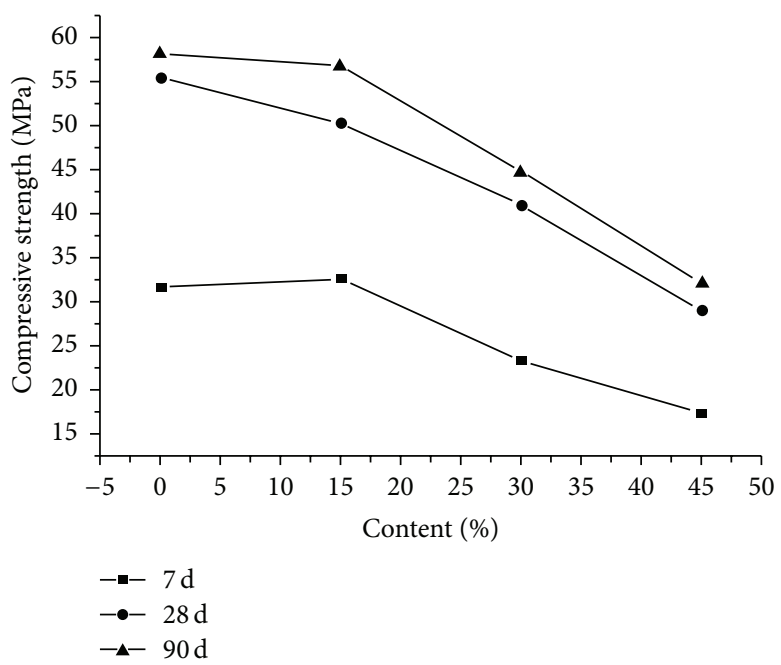

(d) Compressive strength of Group GLS

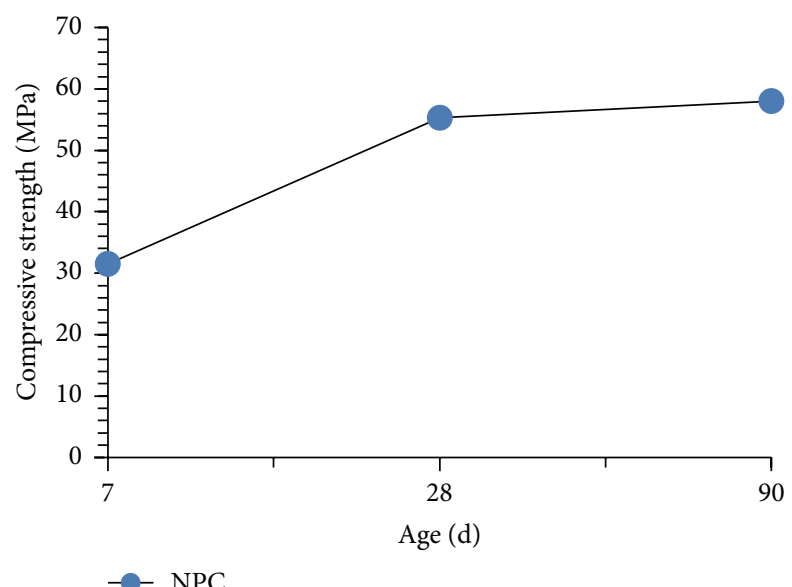

(e) Compressive strength of Group NPC

FIGURE 1: Compressive strength of pastes with different admixtures. 
TABLE 6: Contribution rates of the hydration activity effect.

\begin{tabular}{lcccc}
\hline Samples & $3 \mathrm{~d}$ & $7 \mathrm{~d}$ & $28 \mathrm{~d}$ & $90 \mathrm{~d}$ \\
\hline GL1 & -0.15 & -0.14 & -0.16 & -0.03 \\
GL2 & -0.25 & -0.17 & -0.34 & 0.03 \\
GL3 & -0.21 & -0.40 & -0.16 & 0.17 \\
GS1 & -0.03 & 0.08 & -0.06 & 0.06 \\
GS2 & -0.12 & -0.13 & -0.18 & 0.03 \\
GS3 & -0.15 & -0.25 & -0.12 & 0.06 \\
LS1 & 0.26 & 0.17 & 0.03 & 0.16 \\
LS2 & 0.18 & 0.31 & 0.01 & 0.18 \\
LS3 & 0.10 & 0.13 & -0.03 & 0.12 \\
GLS1 & 0.15 & 0.18 & 0.06 & 0.13 \\
GLS2 & 0.04 & 0.05 & 0.05 & 0.09 \\
GLS3 & 0.05 & -0.01 & -0.05 & 0.00 \\
\hline
\end{tabular}

Therefore, a relative index is obtained which is called the hydration activity contribution rate $\left(P_{a}\right) . P_{a}$ can be used to represent the degree of contribution of the hydration activity effect of gel materials. The calculation formula is

$$
P_{a}=\frac{R_{s p}}{R_{s a}}=\frac{R_{s a}-R_{s c}}{R_{s a}}=1-\frac{R_{s c}}{R_{s a}}=1-\frac{R_{c} * q_{0}}{R_{a} * 100} .
$$

The contribution rates of the hydration activity effect of the test sample mineral admixture of all groups were calculated according to the methodology above. Table 6 shows the calculated results. From Table 6, it is obvious that, for GP, LP, and SP, the cured age and the combined methods all significantly affected hydration activity and strength.

For the trimixed groups, GL and GS mixed with glass powder had a low contribution rate to hydration activity at the early stage. The LS group multimixed with limestone powder and steel slag powder and the GLS group trimixed with glass powder, limestone powder, and steel slag powder showed optimal contribution rate of hydration activity at the early and late stages. This trend was more obvious at $15 \%$ content.

According to the methodology above, the contribution rates of the hydration activity effect of mineral admixture in the test samples of all groups are calculated. Table 3 shows the calculated results. From Table 3, it is obvious that, for GP, LP, and SP, the cured age and the combined methods all have great importance to hydration activity effect on strength.

For the trimixed groups, GL and GS mixed with glass powder have a low contribution rate of hydration activity at the early age. Group LS multimixed with limestone powder and steel slag powder and Group GLS trimixed with glass powder, limestone powder, and steel slag powder have optimal contribution rate of hydration activity both at the early age and at the late age. This rule is more obvious at content of $15 \%$.

3.3. XRD Analysis. Figures 2 and 3 show the details of the measured XRD patterns. The combined content of glass powder and limestone powder, glass powder and steel slag powder, or limestone powder and steel slag powder had identical diffraction peak positions but different peak values.

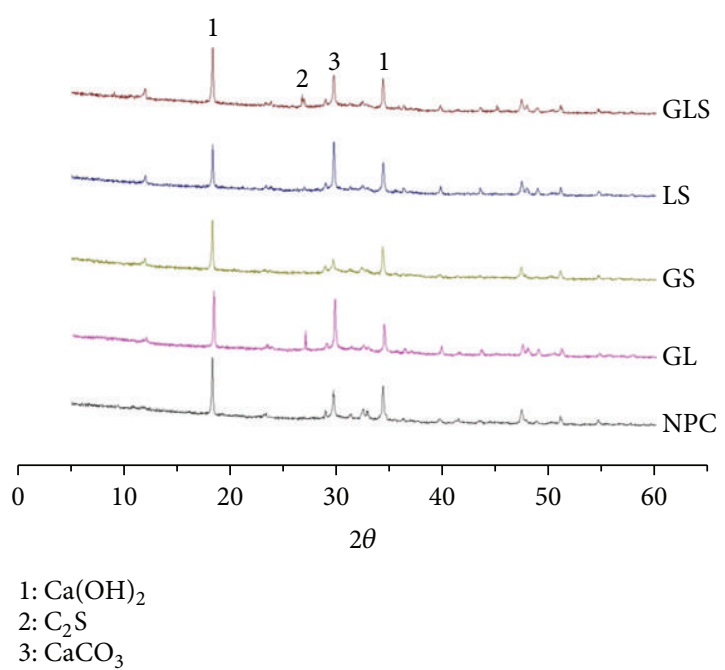

Figure 2: XRD results of samples at $28 \mathrm{~d}$.

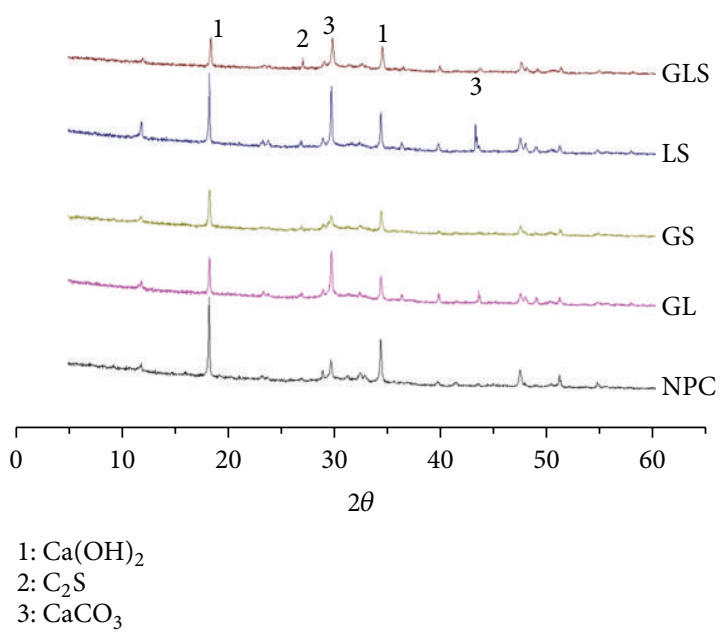

Figure 3: XRD results of samples at $90 \mathrm{~d}$.

This shows that the constitutions (i.e., mainly $\mathrm{Ca}(\mathrm{OH})_{2}$, unhydrated clinker, and a small amount of $\mathrm{CaCO}_{3}$ generated via carbonization) of all the groups with different mineral admixtures were basically the same. It can be observed from the graphs that the $\mathrm{Ca}(\mathrm{OH})_{2}$ diffraction peaks at 28 days were evident. This shows that cement at 28 days hydrated fully and showed good crystallinity under combined content conditions. The $\mathrm{C}_{2} \mathrm{~S}$ and $\mathrm{C}_{3} \mathrm{~S}$ diffraction peaks were low at 90 days and also lower than those at 28 days. The implication is that the dicalcium silicate and tricalcium silicate hydrated over time, while the cement at 90 days had not fully hydrated.

For the trimixed cement with glass powder, limestone powder, and slag powder, the $\mathrm{Ca}(\mathrm{OH})_{2}$ content at 28 days had the highest diffraction peak. This is due to two reasons: first, cement hydration was sufficient under trimixed conditions because the triple-mixed mineral admixture enhanced cement hydration at the early stage, generating more $\mathrm{Ca}(\mathrm{OH})_{2}$; this agrees with the strength test results. Second, glass powder was activated under certain alkaline 


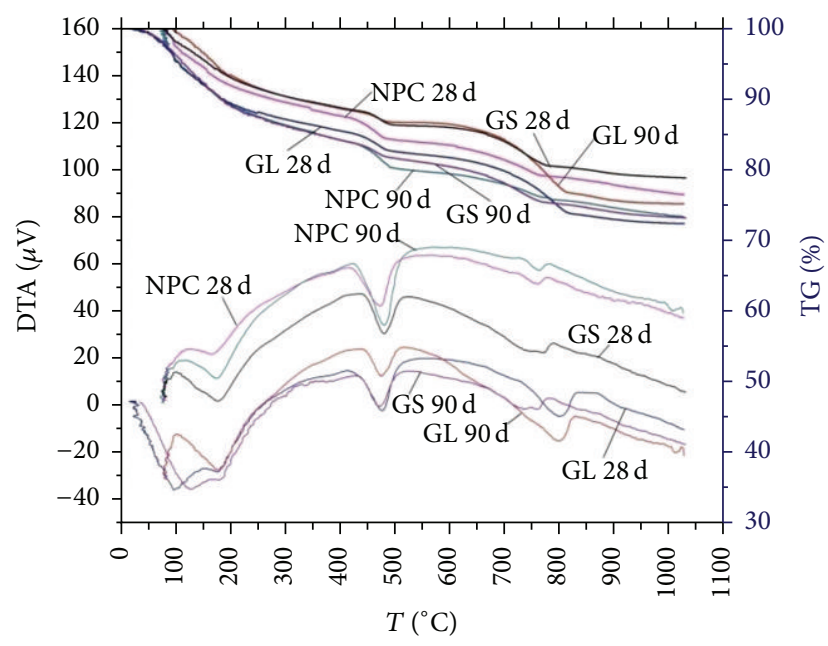

FIGURE 4: TG-DTA curves of samples.

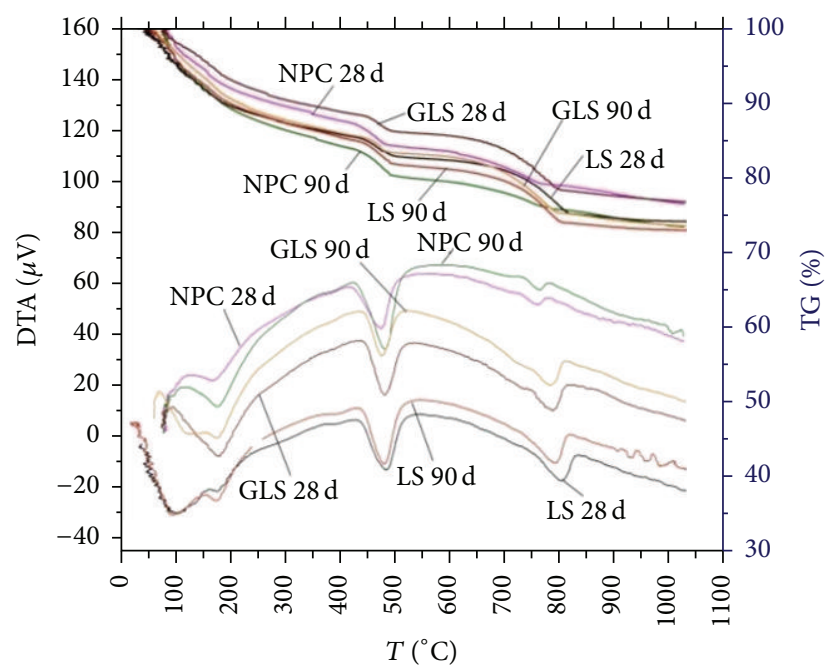

FIGURE 5: TG-DTA curves of samples.

environments, so glass powder activity at the early stage was low and $\mathrm{Ca}(\mathrm{OH})_{2}$ consumption was very limited.

At the early hydration stage (before $28 \mathrm{~d}$ ), incorporating different mineral admixtures did not significantly change the kinds of systematic hydration products; however, the number of hydration products changed obviously. Over time, groups mixed with glass powder impressively dropped $\mathrm{Ca}(\mathrm{OH})_{2}$ content at $90 \mathrm{~d}$. This is because, at the later hydration stage, the alkali concentration of the pore solution gradually increased, which promoted pozzolanic activity and consumed partial $\mathrm{Ca}(\mathrm{OH})_{2}$. In these test samples, the unhydrated clinkers such as dicalcium silicate and tricalcium silicate had lower diffraction peaks compared to the other groups, showing that the cement hydration was relatively sufficient.

3.4. TG-DTA. $\mathrm{Ca}(\mathrm{OH})_{2}$ contents would be quantitatively calculated from TG-DTA results (Figures 5 and 6). The different systems had different $\mathrm{Ca}(\mathrm{OH})_{2}$ contents and different weight loss ratios. Figure 4 shows the calculated results.

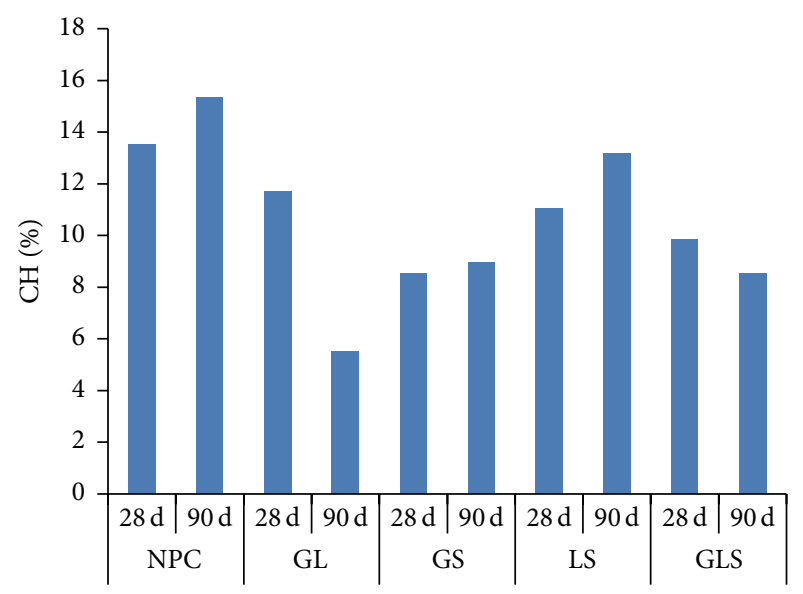

Figure 6: $\mathrm{Ca}(\mathrm{OH})_{2}$ content of samples.

Take a comparison of multimixed admixture and complex admixtures; it could be seen that the amount of calcium hydroxide would be decreased by adding glass powder. At the same time, the amount of calcium hydroxide would be increased by adding limestone powder or steel powder.

3.5. SEM Analysis. $30 \%$ content from each group was taken as characteristic specimens of the group. As can be seen from Figure 7 (NPC group), all kinds of slurry are lapped from each other in the cement paste at the age of $28 \mathrm{~d}$, not as dense as the pores which exist at the join parts of the crystal making the structure appear loose. In addition, the formed calcium hydroxide crystal in the loose holes crossed between the various gels with enough developmental space and seemed significantly larger under an electron microscope. Cement hydration increased significantly, and the constantly generated hydration products filled into the original loose holes over time. The hexagonal calcium hydroxide crystal in slurry was mostly combined with the hydrated calcium silicate (CSH) gel to form a dense structure as a whole. The results are consistent with those of XRD and TG-DTA.

There are a large number of hexagonal layered calcium hydroxide crystals with mesh and granular CSH gel in slurry multimixed with glass powder and limestone powder (Figures 7(c) and 7(d)) (Group GL). It can also be observed that CSH gel filled each pore. The surface of the glass powder began to be eroded with hydration product enrichment on its surface, indicating the occurrence of the pozzolanic reaction. The hydrated structure was relatively dense compared with the pure cement test block at the same age, which closely related to the fine gradation of the multivariate gelling system. From the morphology at $90 \mathrm{~d}$, the constantly generated hydration products filled the pores over time to form a more solid product. Calcium hydroxide crystals were not a single crystal structure but showed laminated cross direction with the CSH gel. Various hydration products alternated to form a denser structure due to the late hydration products of the glass powder, steel slag, and limestone powder reaction filling the pores; this is consistent with the $\mathrm{XRD}$ analysis. 


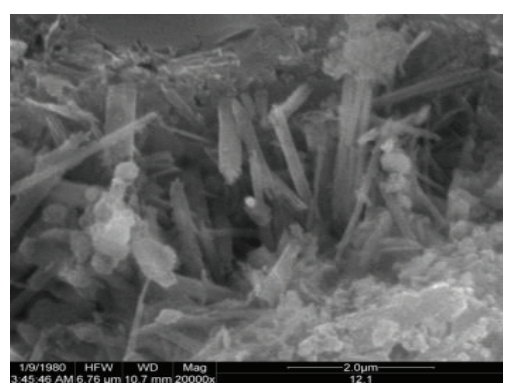

(a)

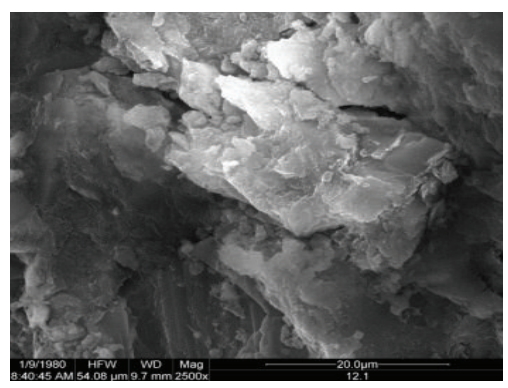

(d)

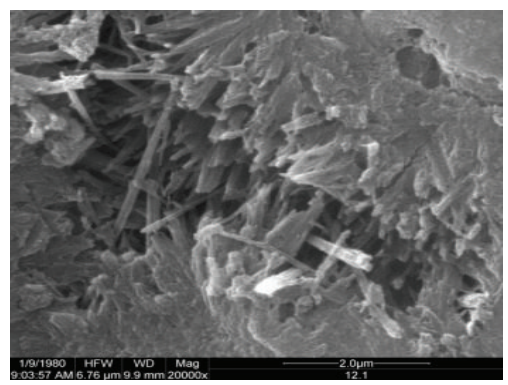

(g)

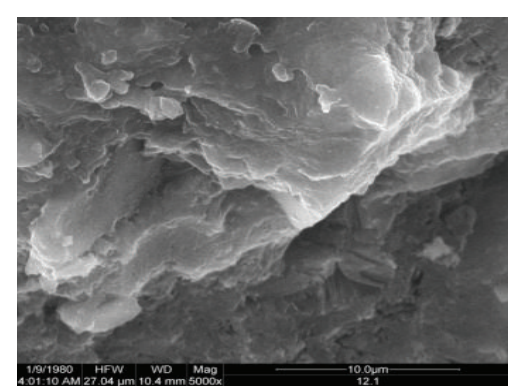

(b)

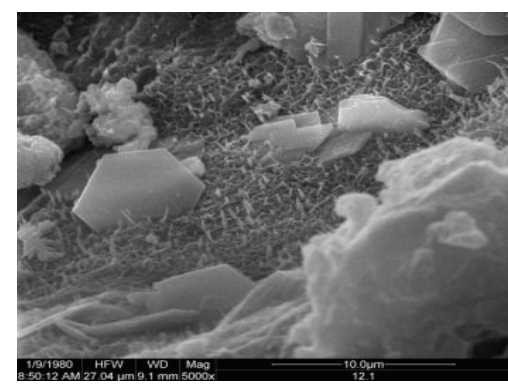

(e)

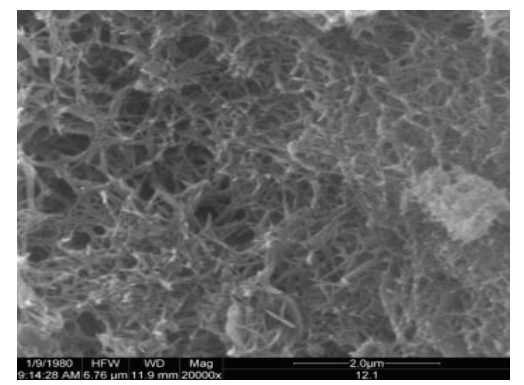

(h)

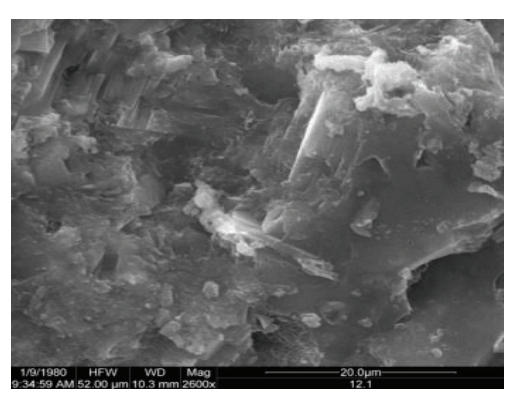

(j)

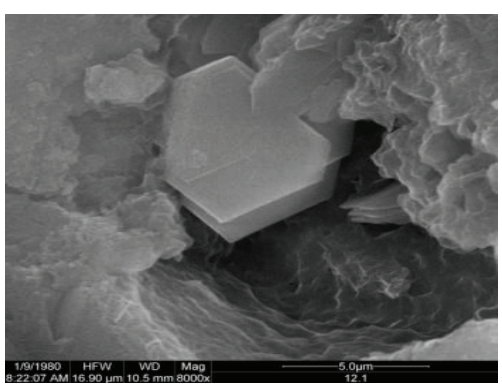

(c)

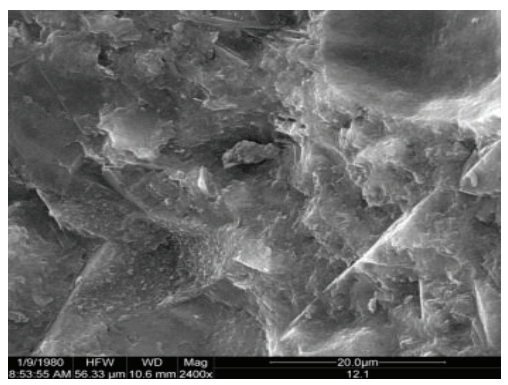

(f)

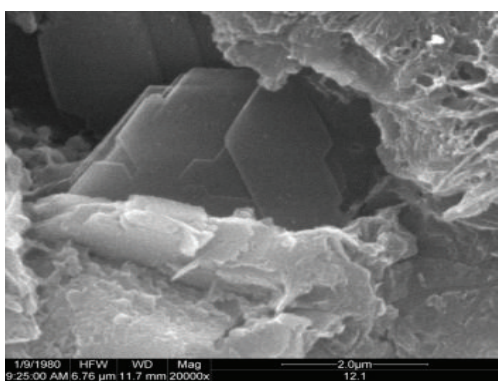

(i) 
be that limestone powder and steel slag powder underwent hydration at the late stage, leading to changes in the original morphology, or that the development of the surrounding hydration products caused them to be wrapped in CSH gel.

Figures 7(i) and 7(j) (Group GLS) show the microscopic hydration morphology of specimens trimixed with glass powder, limestone powder, and steel slag powder at 28 and $90 \mathrm{~d}$, respectively. From Figure 7(i), there existed a large number of $\mathrm{CSH}$ gels, calcium hydroxide, and hydration products that mutually alternated as a whole. In contrast to the microscopic morphology of other groups at $28 \mathrm{~d}$, the early stage structure was denser with less pore distribution. The reason is that the gradation of the four-element gelling system (i.e., the cement, glass powder, lime stone powder, and steel slag powder) was further optimized to act as a micro aggregate fully and enhanced the compressive strength of the slurry; this is consistent with the strength test results. At $90 \mathrm{~d}$, the hydration degree of the four kinds of cementbased materials increased with various constantly generated hydration products, which filled the pores. As a result, the system formed a dense structure and it was thus difficult to observe the hydration products with distinct morphology.

\section{Conclusions}

Therefore, we conclude the following:

(1) The early strength development of glass powder incorporated into the GL and GS specimens was poor but grew rapidly at later stages. The trimixed specimens with glass powder, limestone powder, and slag powder showed the ideal ratio. Also, the strength development of the system showed a good developmental trend from the early to the late stage due to the four-element gelling system, which was further optimized. When the content reached $45 \%$, the pore solution alkalinity could not arouse the high hydration degree of the glass powder for the insufficient cement content and the lack of hydration products.

(2) The multiple gelling systems with multi- or trimixing mineral admixtures further improved the coarse aggregate grading diameter. The micro aggregate acted fully to make nonhydrated particles and aggregates fill the pores, which reduced slurry porosity and closely connected with the cement hydration products to enhance its early strength. The pozzolanic reaction occurred in the late components of the composite powder to consume part of the calcium hydroxide produced by cement hydration and also improved its hydration environment. At the same time, the generated CSH gels made the structure denser, thereby improving the structure strength.

(3) Based on this research, the optimal composite institution and the mineral admixture content proportions were obtained, which could provide a new way of using mineral admixtures in concrete.

\section{Competing Interests}

The authors declare that they have no competing interests.

\section{Acknowledgments}

This project is funded by the National Natural Science Foundation of China (51208391 and 51539002), the Opening Funds of Guangxi Key Laboratory of New Energy and Building Energy Saving (11-03-21-13), and China Postdoctoral Science Foundation (no. 2015M582213).

\section{References}

[1] C. D. Johnston, "Waste glass as coarse aggregate for concrete," Journal of Testing and Evaluation, vol. 2, no. 5, pp. 344-350, 1974.

[2] W. Jin, C. Meyer, and S. Baxter, "Glascrete-concrete with glass aggregates," ACI Materials Journal, vol. 97, pp. 208-213, 2000.

[3] Z. P. Bažant, G. Zi, and C. Meyer, "Fracture mechanics of ASR in concretes with waste glass particles of different sizes," Journal of Engineering Mechanics, vol. 126, no. 3, pp. 226-232, 2000.

[4] Entec Consulting Ltd, Report on Ontario Blue Box Material Recovery Facilities, 2007.

[5] H.-Y. Wang and W.-L. Huang, "Durability of self-consolidating concrete using waste LCD glass," Construction and Building Materials, vol. 24, no. 6, pp. 1008-1013, 2010.

[6] A. Shayan and A. Xu, "Value-added utilisation of waste glass in concrete," Cement and Concrete Research, vol. 34, no. 1, pp. 81$89,2004$.

[7] S. K. Das, A. K. Sharma, F. C. Parida, and N. Kasinathan, "Experimental study on thermo-chemical phenomena during interaction of limestone concrete with liquid sodium under inert atmosphere," Construction and Building Materials, vol. 23, no. 11, pp. 3375-3381, 2009.

[8] T. Schmidt, B. Lothenbach, M. Romer, K. Scrivener, D. Rentsch, and R. Figi, "A thermodynamic and experimental study of the conditions of thaumasite formation," Cement and Concrete Research, vol. 38, no. 3, pp. 337-349, 2008.

[9] P. Pipilikaki, D. Papageorgiou, M. Dimitroula, E. Chaniotakis, and M. Katsioti, "Microstructure changes in mortars attacked by sulphates at 5०C," Construction and Building Materials, vol. 23, no. 6, pp. 2259-2264, 2009.

[10] F. Girardi, W. Vaona, and R. Di Maggio, "Resistance of different types of concretes to cyclic sulfuric acid and sodium sulfate attack," Cement and Concrete Composites, vol. 32, no. 8, pp. 595602, 2010.

[11] N. Schwarz and N. Neithalath, "Influence of a fine glass powder on cement hydration: comparison to fly ash and modeling the degree of hydration," Cement and Concrete Research, vol. 38, no. 4, pp. 429-436, 2008.

[12] O. Hajime and O. Masahiro, "Self-coMPacting concrete: development, present use and future," in Proceedings of the 1st International RILEM Symposium on Self-CoMPacting Concrete, pp. 3-14, Stockholm, Sweden, 1999.

[13] M. Sonebi, "Medium strength self-compacting concrete containing fly ash: modelling using factorial experimental plans," Cement and Concrete Research, vol. 34, no. 7, pp. 1199-1208, 2004.

[14] G. Kakali, S. Tsivilis, E. Aggeli, and M. Bati, "Hydration products of $\mathrm{C}_{3} \mathrm{~A}, \mathrm{C}_{3} \mathrm{~S}$ and Portland cement in the presence of 
$\mathrm{CaCO}_{3}$," Cement and Concrete Research, vol. 30, no. 7, pp. 10731077, 2000.

[15] New Slag Association, “Cement Americas,” May 2001.

[16] R. S. Kalyoncu, "Iron and steel slag," in Mineral Commodity Summaries, pp. 92-93, U.S. Geological Suvrey, 2003.

[17] H. Motz and J. Geiseler, "Products of steel slags an opportunity to save natural resources," Waste Management, vol. 21, no. 3, pp. 285-293, 2001.

[18] J. N. Murphy, T. R. Meadowcroft, and P. V. Barr, "Enhancement of the cementitious properties of steelmaking slag," Canadian Metallurgical Quarterly, vol. 36, no. 5, pp. 315-331, 1997.

[19] D. Niu, L. Jiang, and Q. Fei, "Deterioration mechanism of sulfate attack on concrete under freeze-thaw cycles," Journal Wuhan University of Technology, Materials Science Edition, vol. 28, no. 6, pp. 1172-1176, 2013.

[20] S. Zhang, L. Li, and A. Kumar, Materials Characterization Techniques, CRC Press, Boca Raton, Fla, USA, 2008.

[21] Q. B. Yang, S. Zhang, S. Huang, and Y. He, "Effect of ground quartz sand on properties of high-strength concrete in the steam-autoclaved curing," Cement and Concrete Research, vol. 30, no. 12, pp. 1993-1998, 2000.

[22] M.-C. Chen, K. Wang, and L. Xie, "Deterioration mechanism of cementitious materials under acid rain attack," Engineering Failure Analysis, vol. 27, pp. 272-285, 2013.

[23] C. Shi, A. F. Jiménez, and A. Palomo, "New cements for the 21st century: the pursuit of an alternative to Portland cement," Cement and Concrete Research, vol. 41, no. 7, pp. 750-763, 2011. 

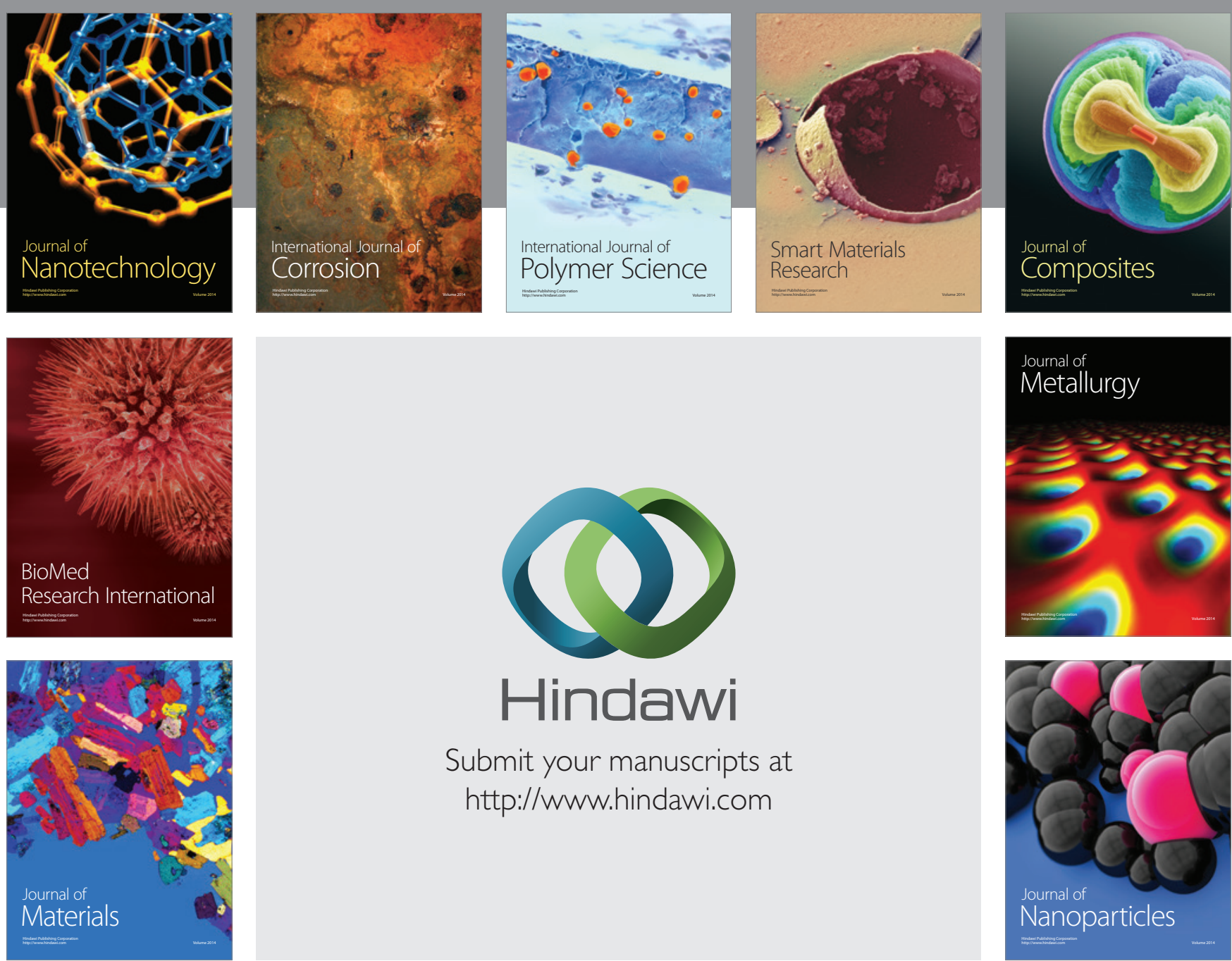

\section{Hindawi}

Submit your manuscripts at

http://www.hindawi.com

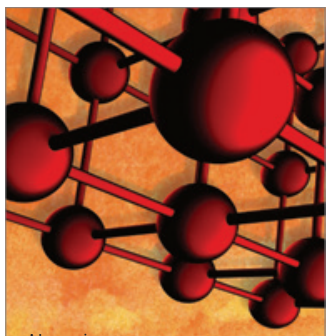

Materials Science and Engineering
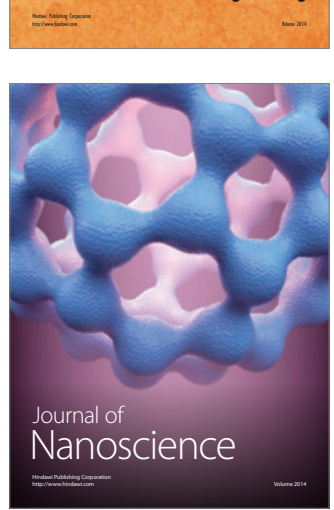
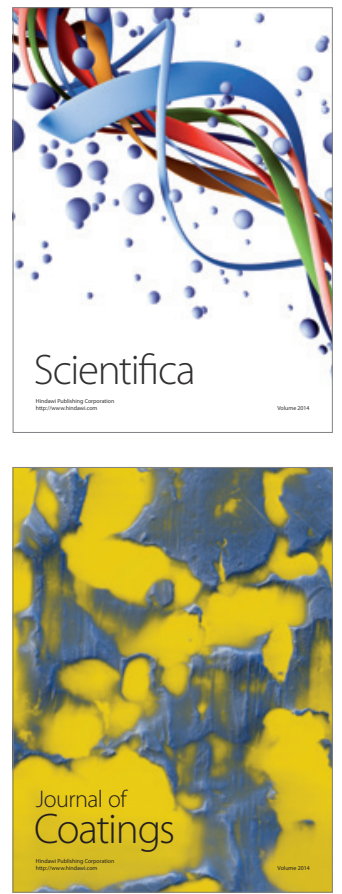
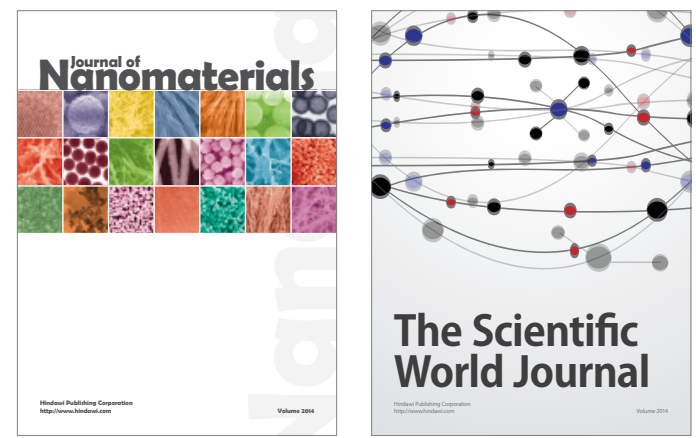

The Scientific World Journal
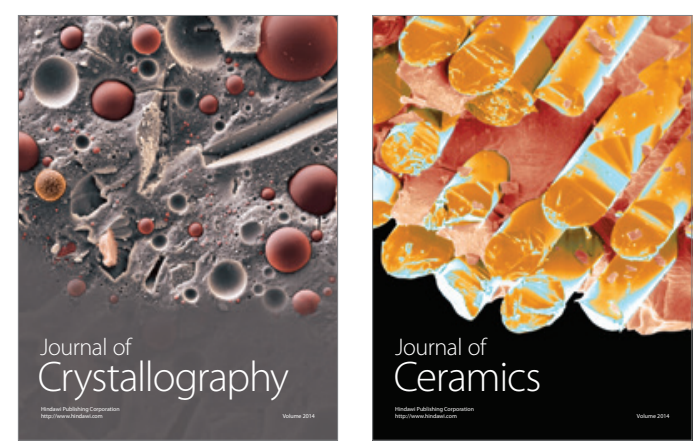
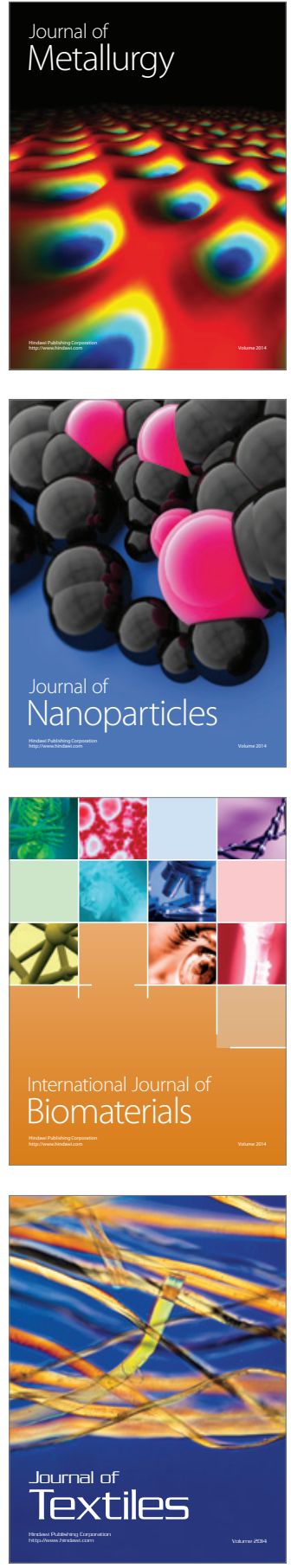